Supporting Information

\title{
Modularized Tuning of Charge Transport through Highly Twisted and Localized Single-molecule Junctions
}

Zhixin Chen, ${ }^{\dagger}$ Lijue Chen, ${ }^{\dagger}$ Jiangpeng Liu, Ruihao Li, Chun Tang, Yuhui Hua, Lichuan Chen, Jia Shi, Yang Yang, Junyang Liu, Jueting Zheng, Lina Chen, Jiankang Cao, Hang Chen, Haiping Xia, ${ }^{*}$ Wenjing Hong*

\section{Table of Contents}

1. Synthesis of compounds

2. NMR spectra of compounds

3. Blank experiment results for pure solvent.

4. Additional experimental data

5. Computational details 


\section{Synthesis of compounds}

N1 and N2 were synthesized via Suzuki cross coupling reactions 9,10-dibromoanthracene (N1) or 1,4-diiodo2,3,5,6-tetramethylbenzene (N2) with pyridine-4-boronic acid. N1A and N2A were synthesized via Sonogashira cross coupling reactions of 4-ethynylpyridine with 1,4-diiodobenzene (N1A) or 9,10-dibromoanthracene (N2A). S1, S2 and So were synthesized via Suzuki cross coupling reactions 9,10-dibromoanthracene (S1), 1,4-diiodo2,3,5,6-tetramethylbenzene (S2) or 1,4-diiodobenzene (S0) with 4-(methylthio)phenylboronic acid. S1A and S2A were synthesized via Sonogashira cross coupling reactions of 1-ethynyl-4-methylsulfanylbenzene with 1,4diiodobenzene (S1A) or 9,10-dibromoanthracene (S2A). All of these products were purified via column chromatography, using dichloromethane / methanol as eluent. All compounds were further purified via recrystallization from dichloromethane / hexane before single-molecule experiments. N0 was purchased from $\mathrm{TCl}$, used directly without further purification.

\section{NMR spectra of compounds}

${ }^{1} \mathrm{H}$ NMR $\left(400.1 \mathrm{MHz}, \mathrm{CDCl}_{3}\right)$ of $\mathbf{N} 1$
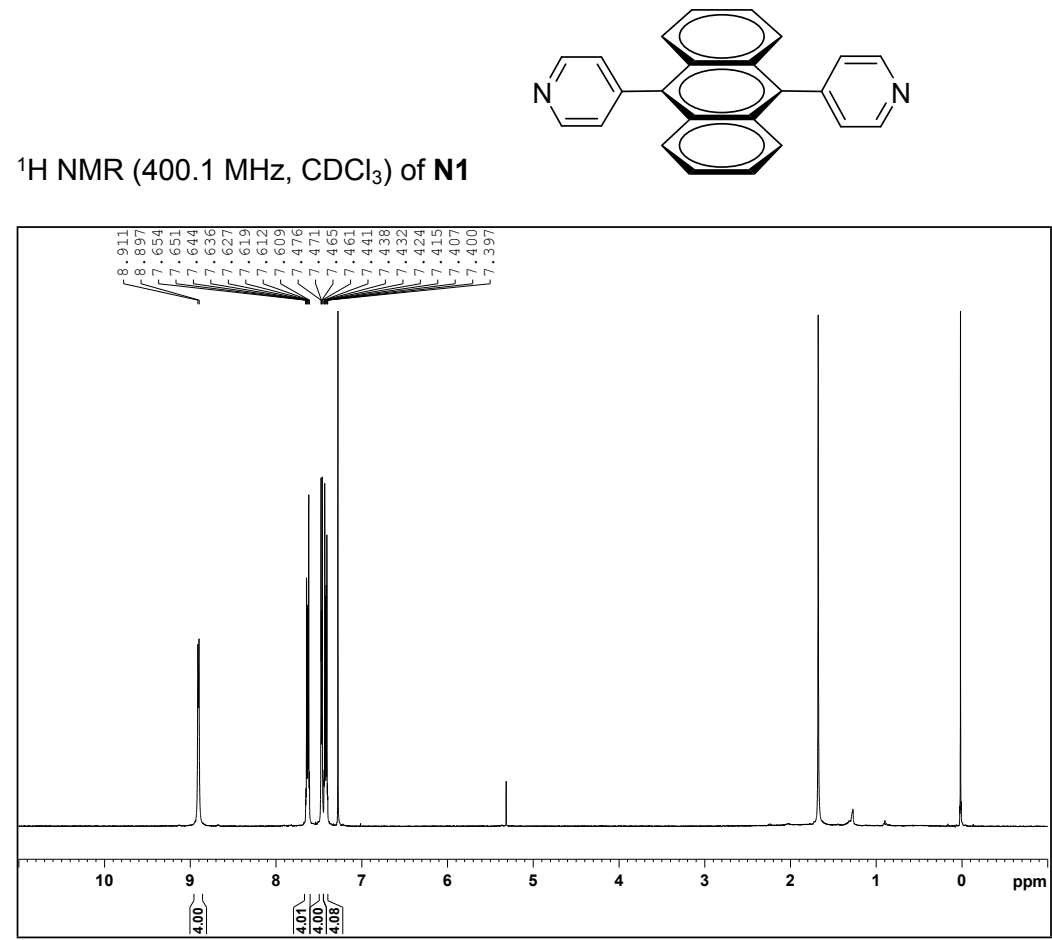

${ }^{1} \mathrm{H}$ NMR $\left(400.1 \mathrm{MHz}, \mathrm{CDCl}_{3}\right)$ of $\mathbf{N} 2$
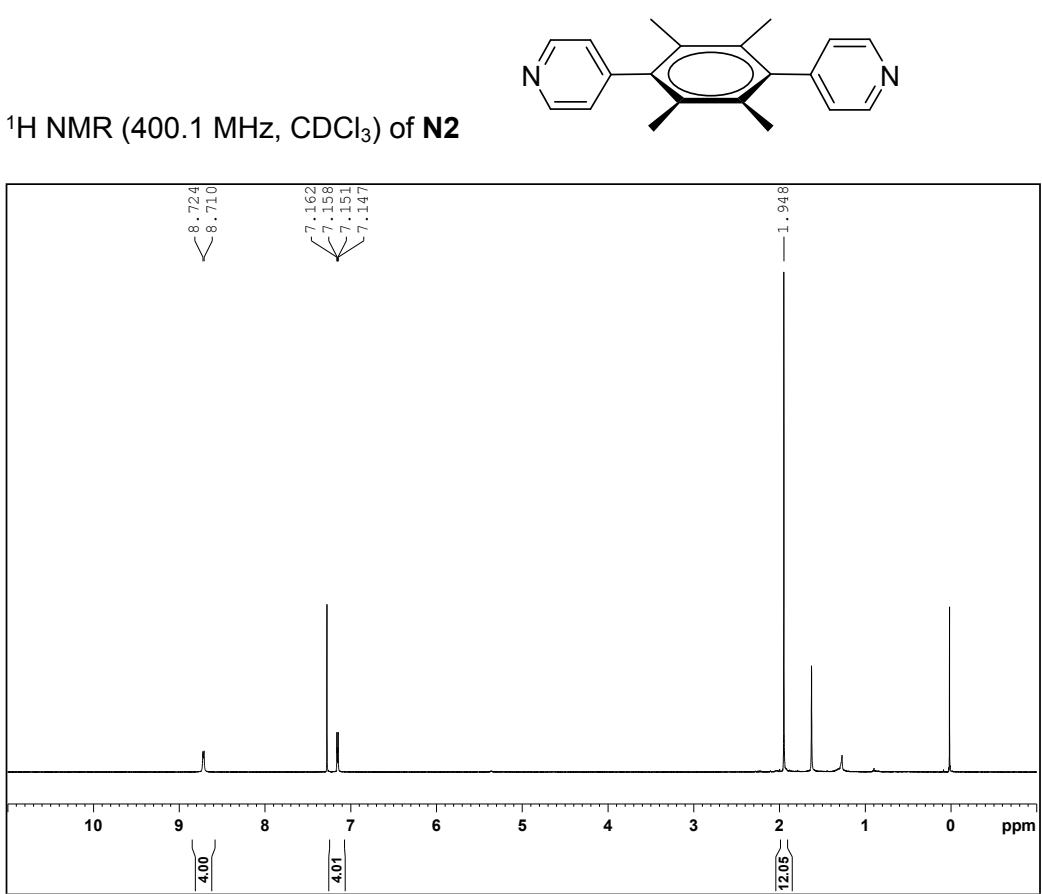
${ }^{1} \mathrm{H}$ NMR $\left(400.1 \mathrm{MHz}, \mathrm{CDCl}_{3}\right)$ of N1A
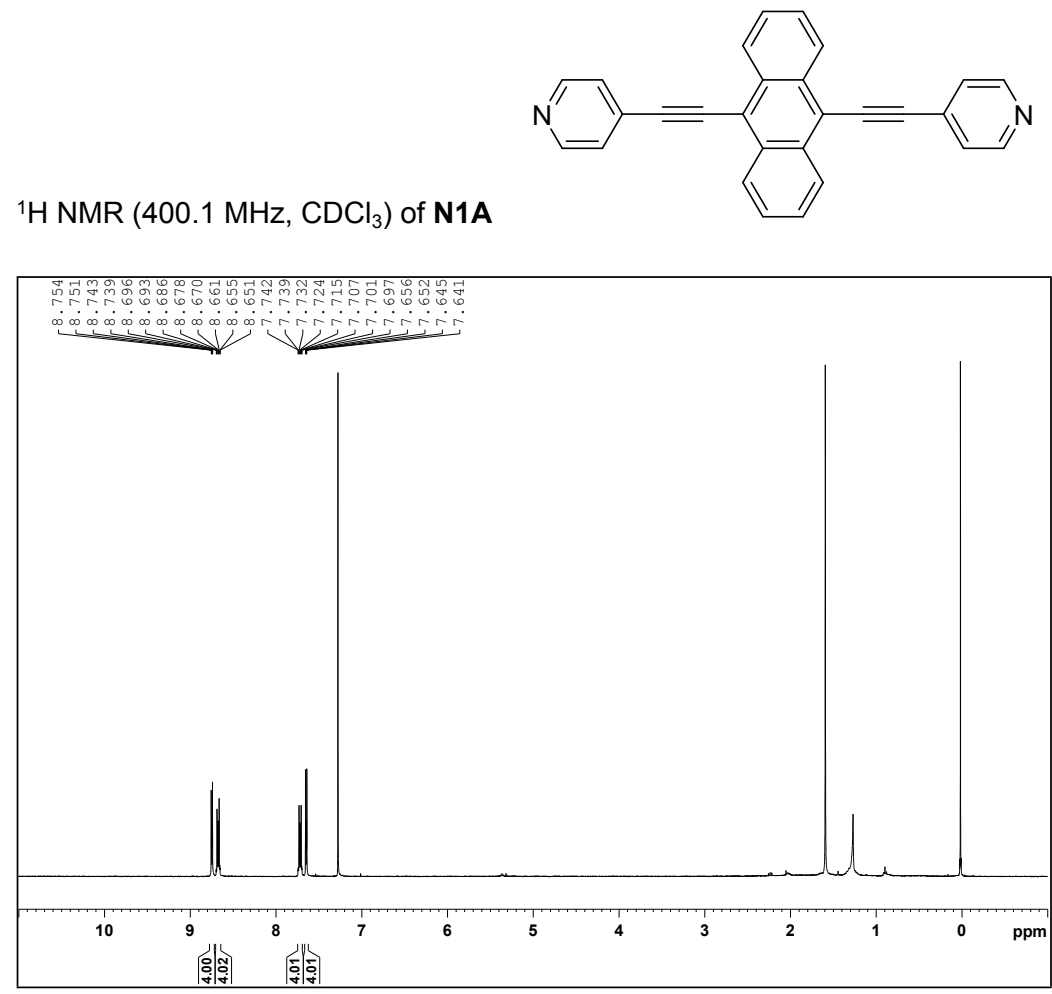

${ }^{1} \mathrm{H}$ NMR $\left(400.1 \mathrm{MHz}, \mathrm{CDCl}_{3}\right)$ of N2A
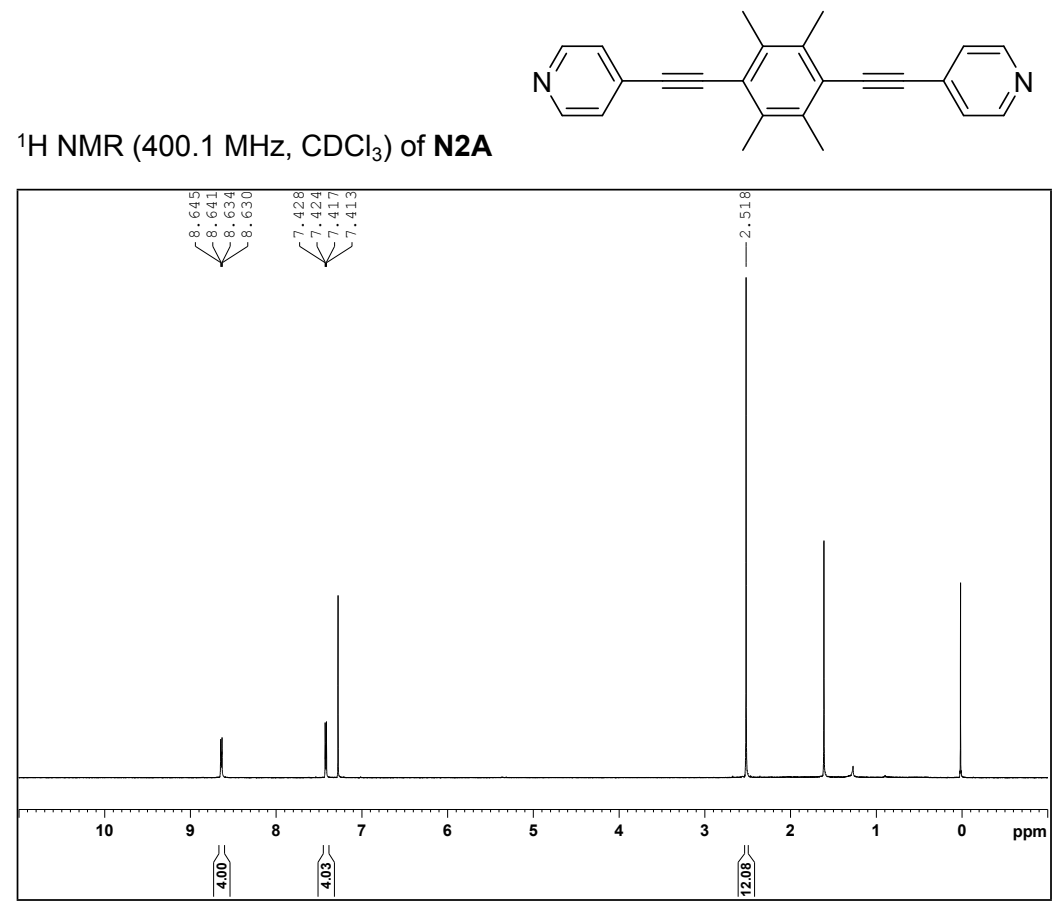
${ }^{1} \mathrm{H}$ NMR $\left(400.1 \mathrm{MHz}, \mathrm{CDCl}_{3}\right)$ of $\mathbf{S 1}$
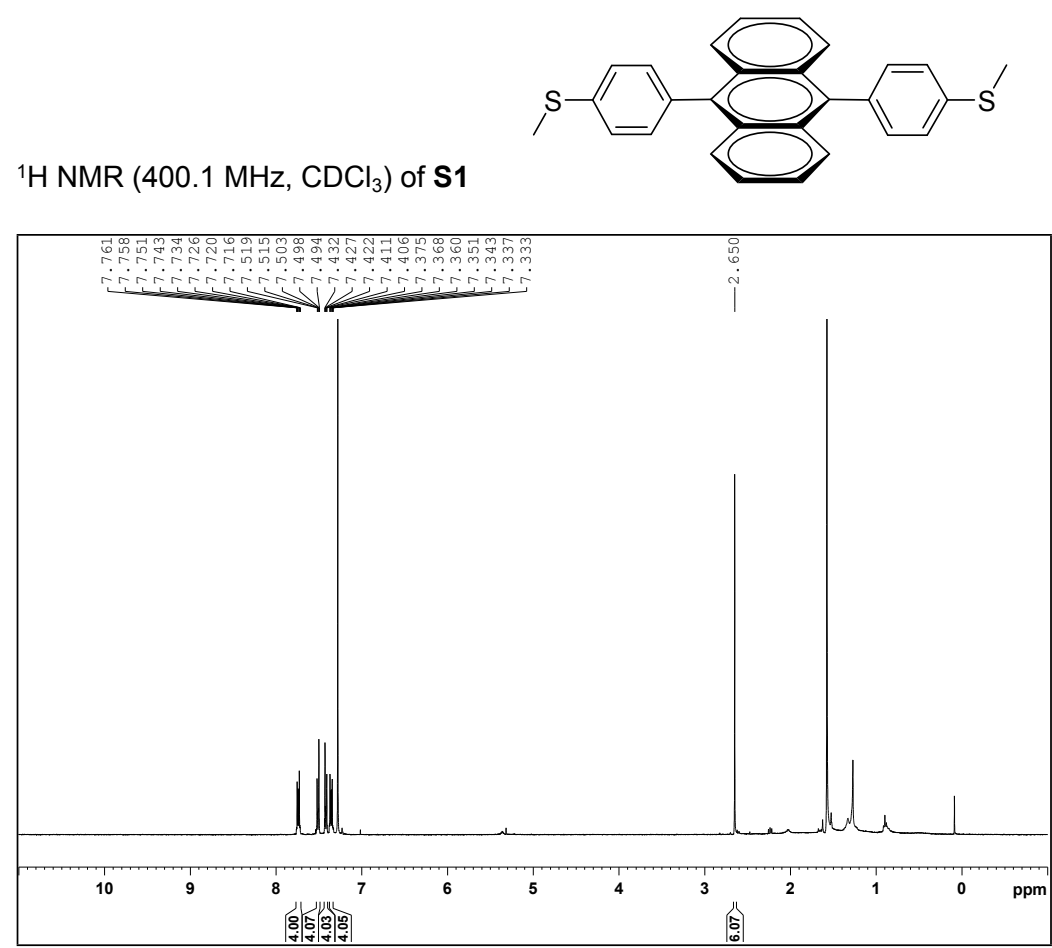

${ }^{1} \mathrm{H}$ NMR $\left(400.1 \mathrm{MHz}, \mathrm{CDCl}_{3}\right)$ of $\mathbf{S 2}$
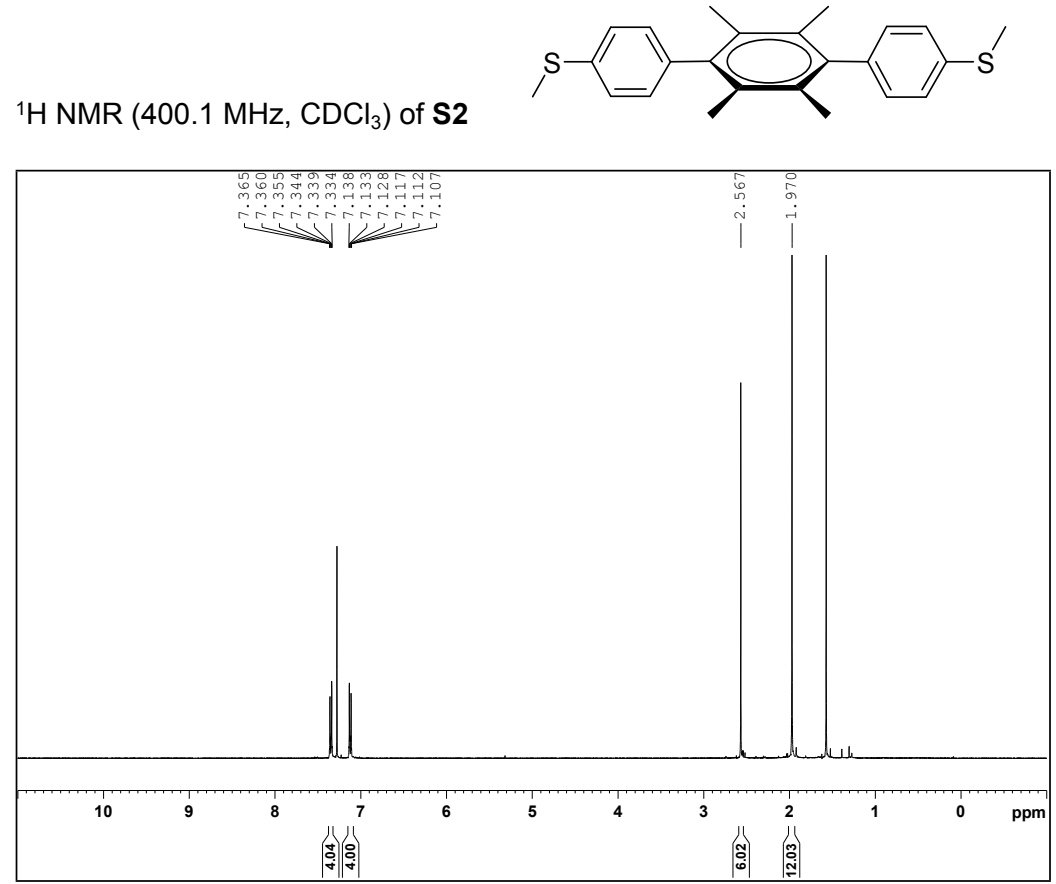
${ }^{1} \mathrm{H}$ NMR $\left(400.1 \mathrm{MHz}, \mathrm{CDCl}_{3}\right)$ of S1A
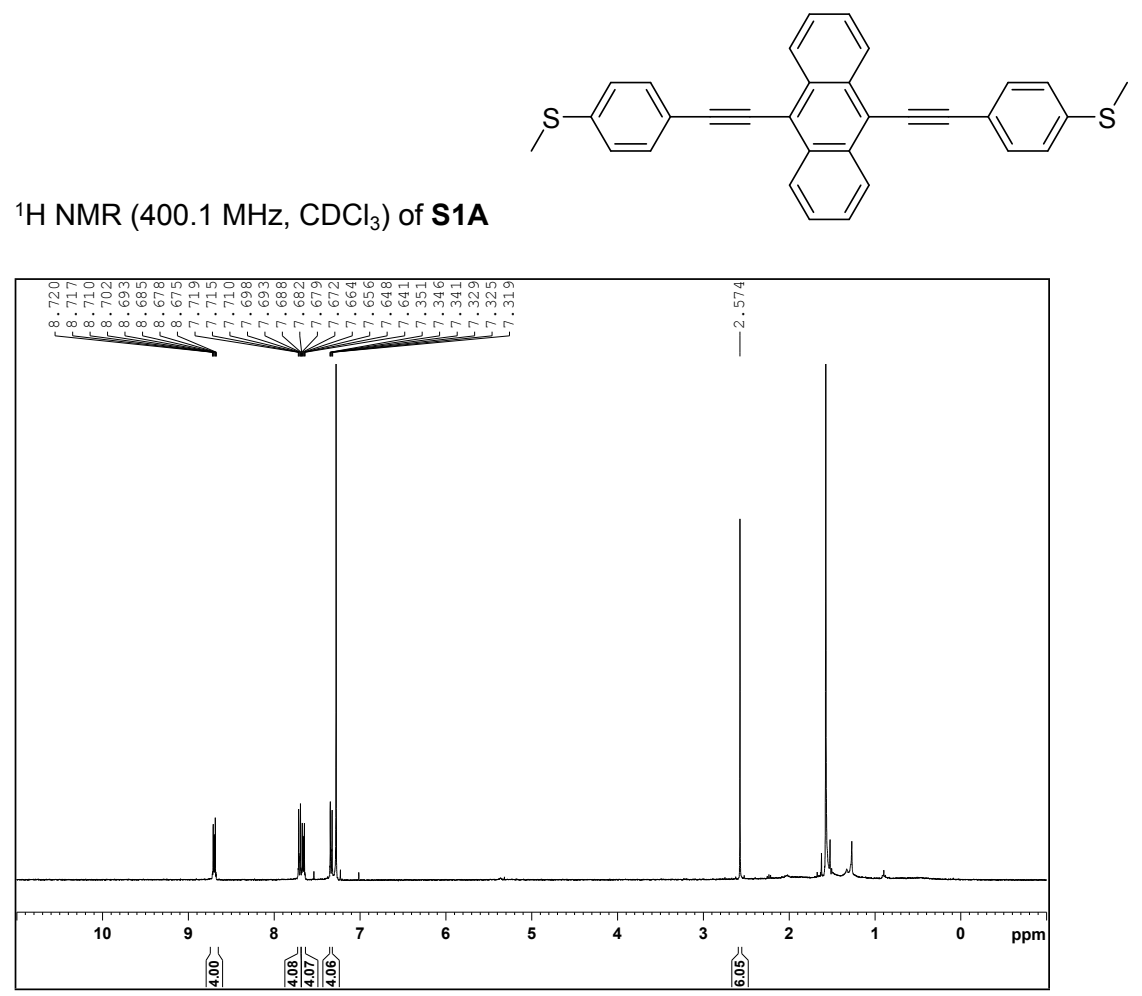

${ }^{1} \mathrm{H}$ NMR $\left(400.1 \mathrm{MHz}, \mathrm{CDCl}_{3}\right)$ of $\mathbf{S 2 A}$
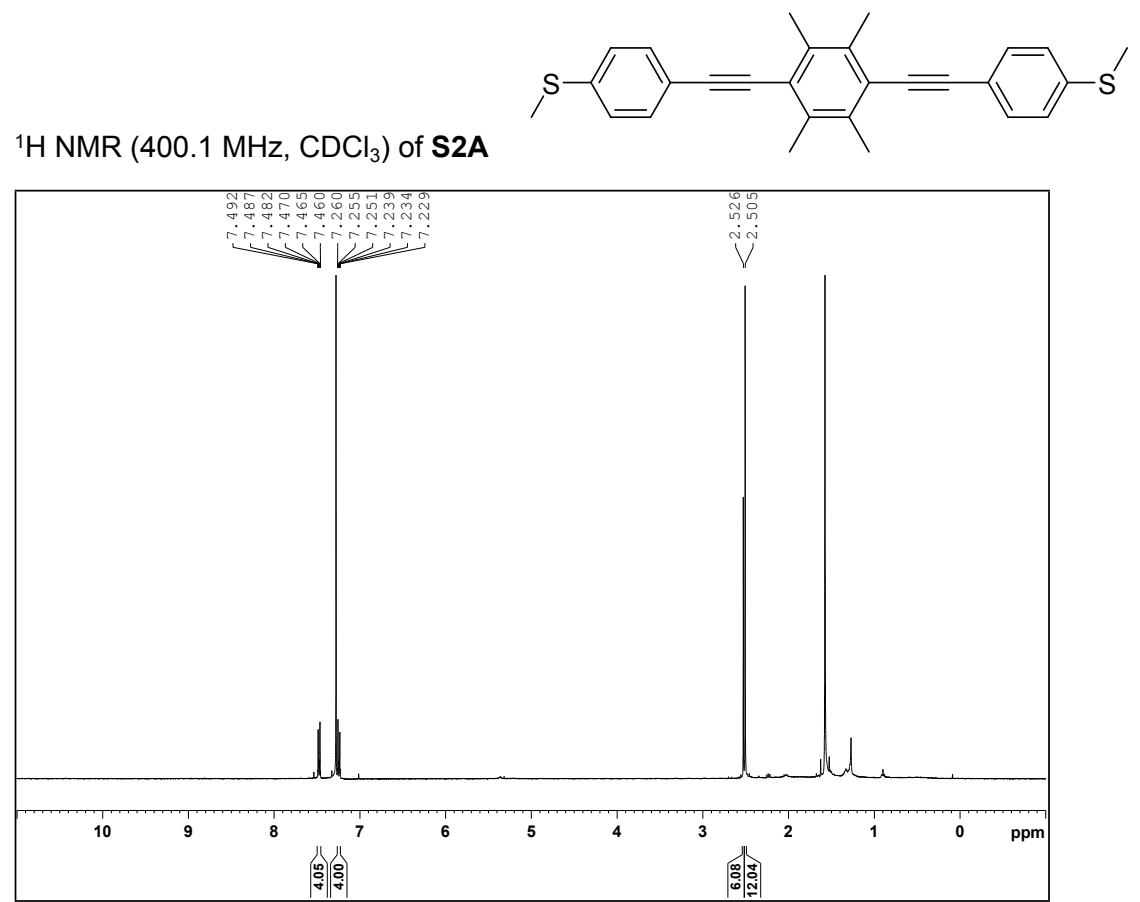


\section{Blank experiment results for pure solvent}

Metallic substrate were generated by evaporating 10-nm-thick chromium and $200-\mathrm{nm}$-thick gold on silicon wafer (China Electronics Technology Group Corporation, CETC) and gold wire (99.999\%, Beijing Jiaming Platinum Nonferrous Metals Pioneer Metals Corporation) for break junction are flamed before use.

We used the mixed solvent of THF/TMB (tetrahydrofuran/1,3,5-trimethylbenzene, $v / v=1: 4$ ) without target molecules as a blank experiment for the calibration of stretching rate of gold tips for STM-BJ experiments. ${ }^{1}$ The $1 \mathrm{D}$ conductance histogram and $2 \mathrm{D}$ conductance versus relative distance $(\Delta \mathrm{z})$ histogram were show in Figure S1. Figure S1a show direct tunneling and clear non-plateau features, suggesting a pure and clean environment inside the tip and substrate. According to the previous measured tunneling decay constant $\left(\log \left[\Delta G / G_{0}\right] / \Delta z=-5.5 \mathrm{~nm}^{-1}\right)$ in the same solvent using STM-BJ technique, ${ }^{2}$ we calibrate the relative displacement in the conductance range from $10^{-3.5}$ to $10^{-5.5} G_{0}$ to be $\sim 0.36 \mathrm{~nm}(-2 /-5.5=\sim 0.36 \mathrm{~nm})$, as shown in Figure S1c.
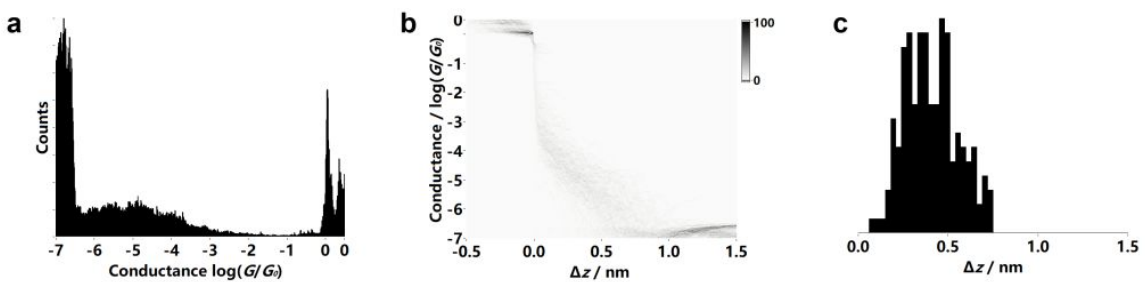

Figure S1. (a) 1D conductance histogram and (b) 2D conductance versus relative distance $(\Delta z)$ histogram of the mixed solvent of THF/TMB $(v / v=1: 4)$. (c) The relative displacement distribution determined from $10^{-3.5}$ to $10^{-5.5} G_{0}$. 


\section{Additional experimental data}

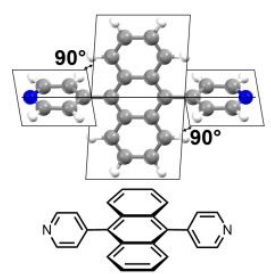

N1

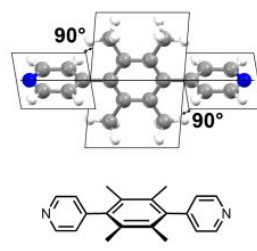

N2

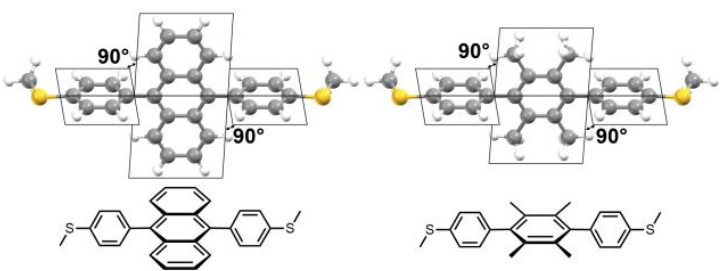

s1

S2
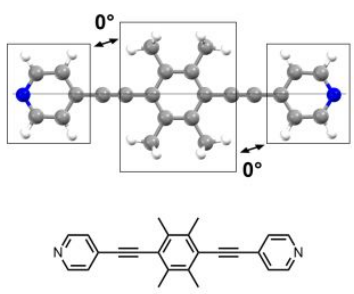

N2A

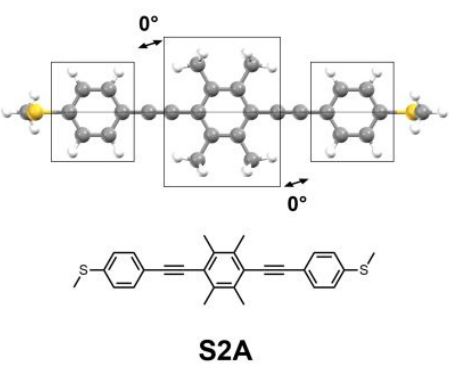

Figure S2. Optimized molecular configurations (DFT calculation, B3LYP/6-311++G**) and chemical structures of molecules investigated in this work. 

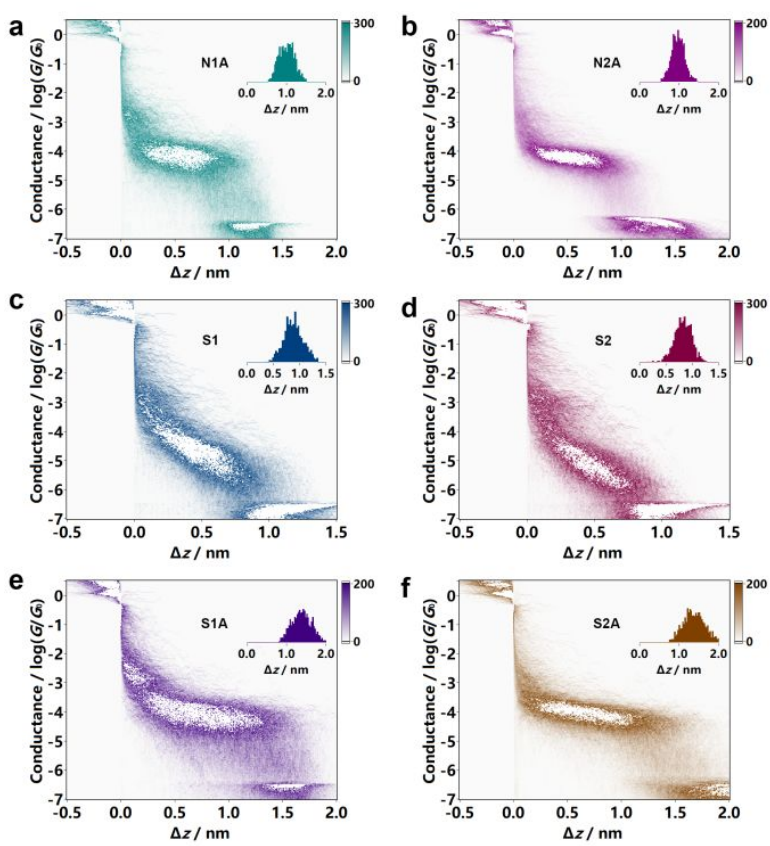

Figure S3. 2D conductance versus relative distance $(\Delta z)$ histograms and relative distance distributions (insert) of (a) N1A, (b) N2A, (c) S1, (d) S2 (e) S1A and (f) S2A. The relative distance distributions are determined from the conductance ranges of $10^{-0.3} G_{0} \sim 10^{-5.8} G_{0}$ for $\mathbf{S 1}, 10^{-0.3} G_{0} \sim 10^{-6.3} G_{0}$ for $\mathbf{S} 2$ and $10^{-0.3} G_{0} \sim 10^{-5.0} G_{0}$ for N1A, N2A, S1A and S2A.

a

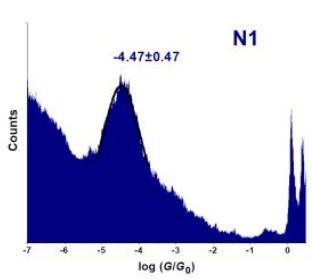

b

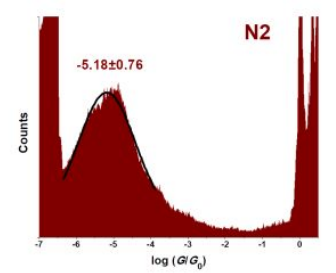

c

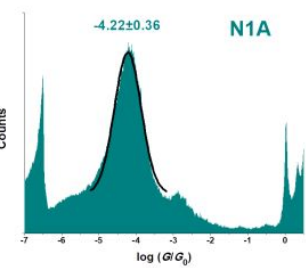

d

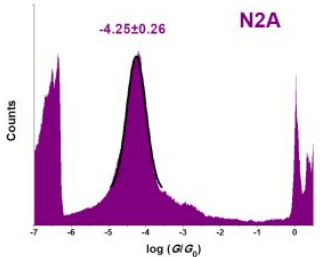

e

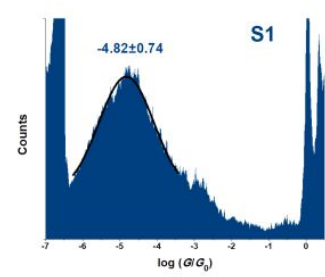

f

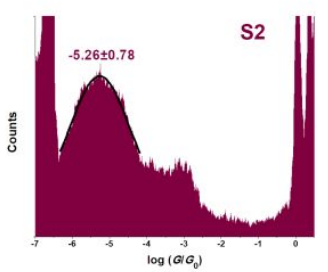

g

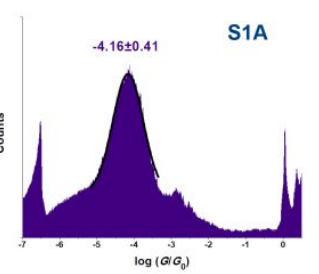

h

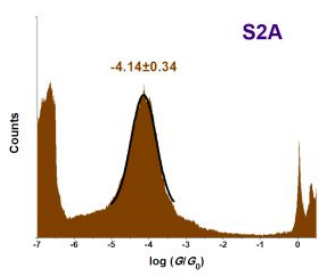


Figure S4. 1D conductance histograms of (a) N1, (b) N2, (c) N1A, (d) N2A, (e) S1, (f) S2, (g) S1A, and (h) S2A with Gaussian curve fitting.

a

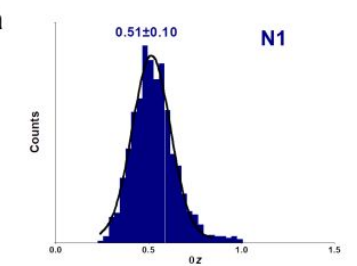

C
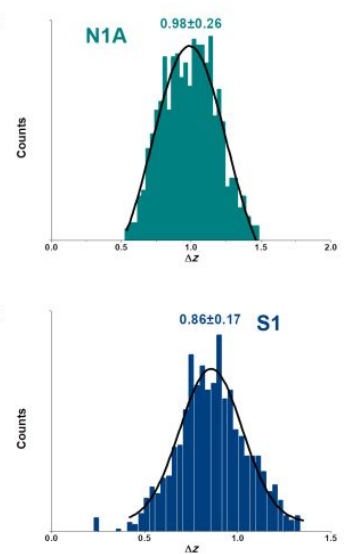

g

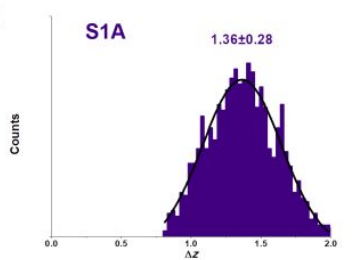

b
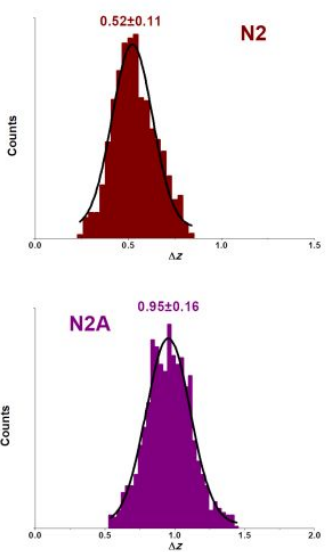

f

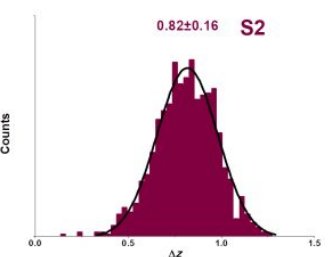

h

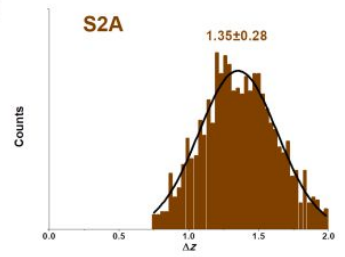

Figure S5. Relative distance ( $\Delta z$ ) distributions of (a) N1, (b) N2, (c) N1A, (d) N2A, (e) S1, (f) S2, (g) S1A, and (h) S2A and (i) S2A with Gaussian curve fitting.
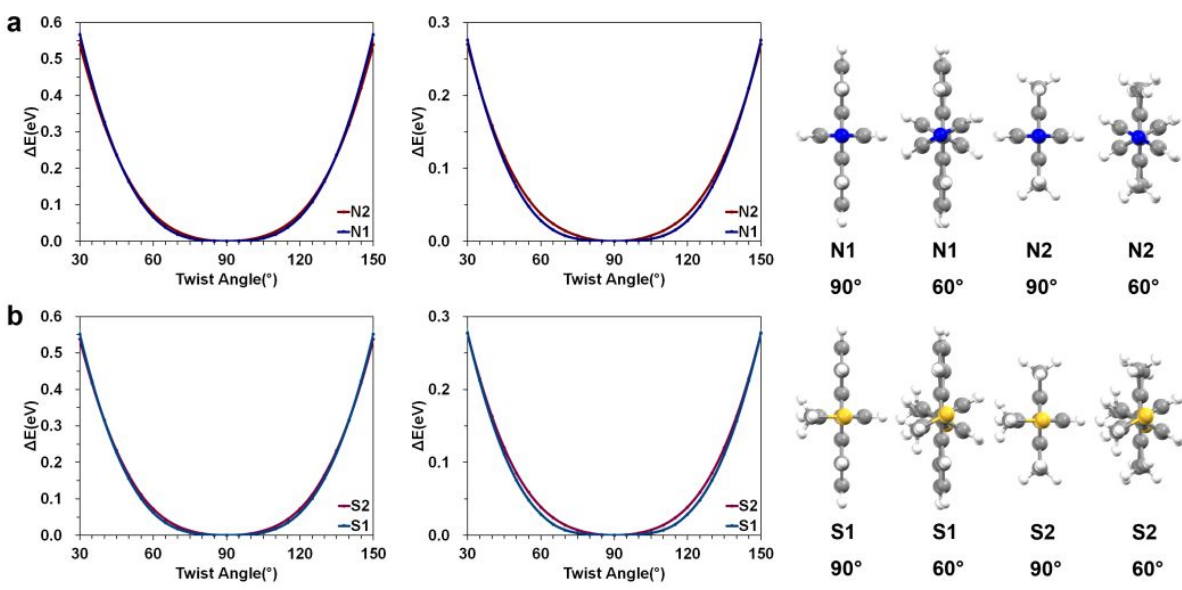

Figure S6. Comparison of rotational barriers between (a) (b) N1 and N2 or (c)(d) S1 and S2 (DFT calculation, B3LYP/6-311++G**). (a) (c) showed symmetric rotational barriers and (b, d) showed antisymmetric rotational barriers. At each twist angle, antisymmetric rotational barrier is lower than symmetric rotational barrier in these 
4 cases, therefore only antisymmetric rotational barriers were discussed. (e) Comparison of antisymmetric rotational barriers of $\mathbf{N 1}, \mathbf{N 2}, \mathbf{S 1}$ and $\mathbf{S 2}$.
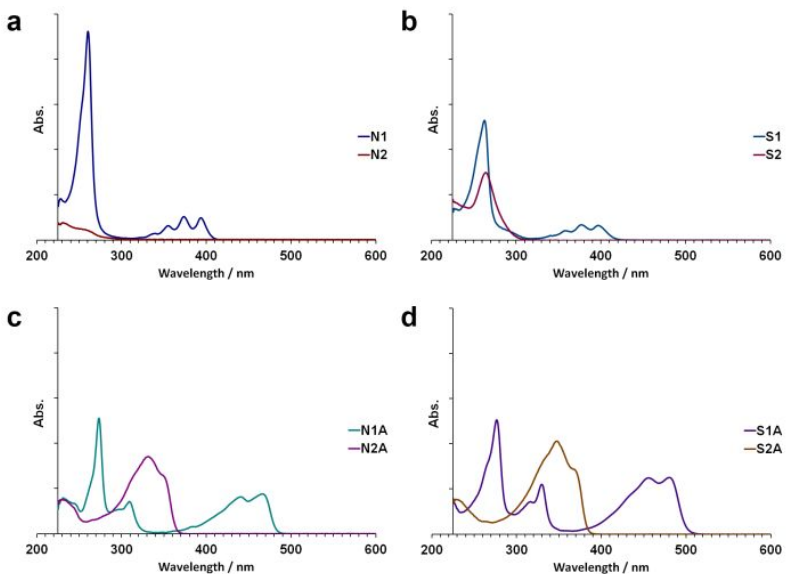

Figure S7. UV-Vis spectra of (a) N1 and N2, (b) S1 and S2, (d) N1A and N2A, (b) S1A and S2A.
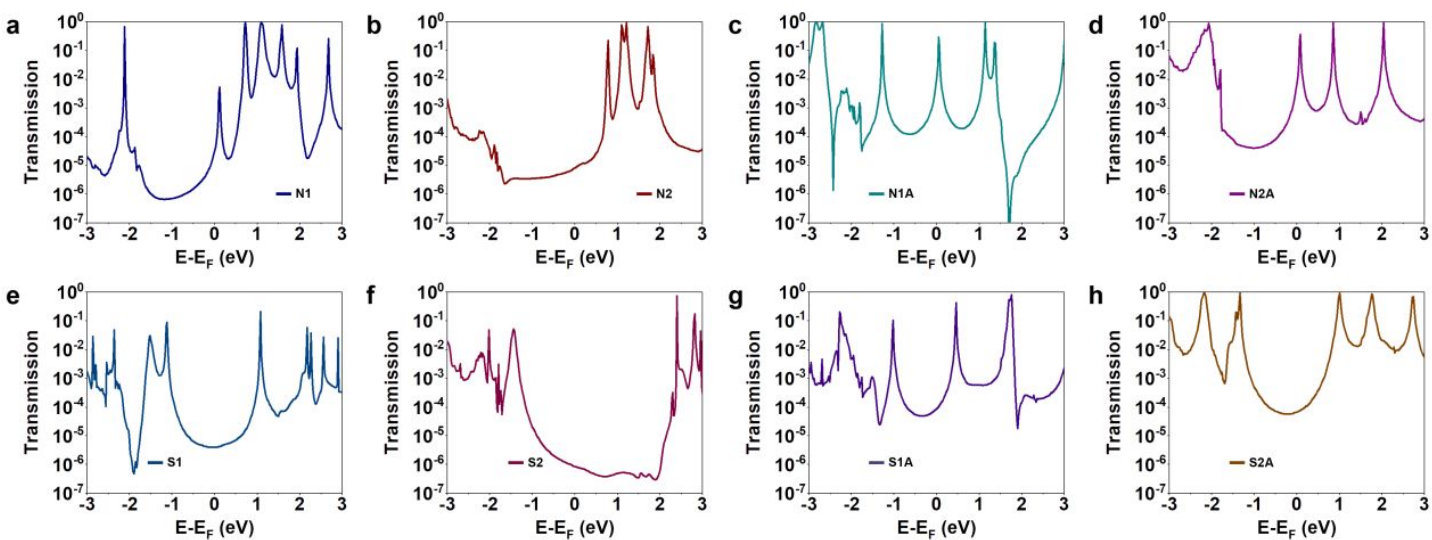

Figure S8. The calculated transmission function of (a) N1, (b) N2 (c) N1A, (d) N2A, (e) S1 (f) S2, (g) S1A, and (h) S2A. 


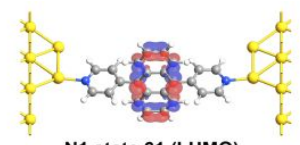

N1 state 61 (LUMO)

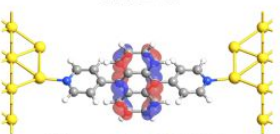

N1 state 60 (HOMO)
$-2.1196 \mathrm{eV}$

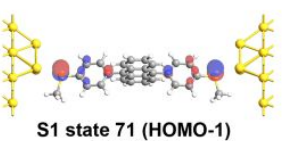

S1 state 71 (HOMO-1)
$-1.3834 \mathrm{eV}$

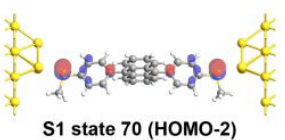
$\mathrm{S} 1$ state $70(\mathrm{HOMO}-2)$
$-1.3888 \mathrm{eV}$

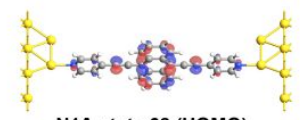

N1A state 68 (HOMO) $-1.2958 \mathrm{eV}$

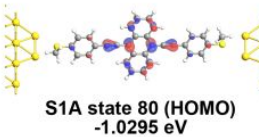

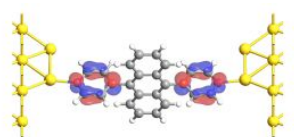

N1 state 63 (LUMO+2)

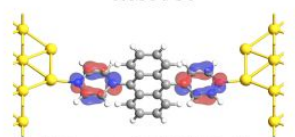

N1 state $62($ LUMO+1)
$+0.6573 \mathrm{eV}$

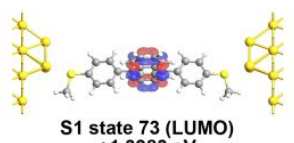

S1 state 73 (LUMO)
$+1.3983 \mathrm{eV}$

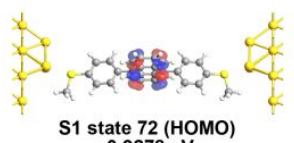
state 72 (HOMO
$-0.9278 \mathrm{eV}$

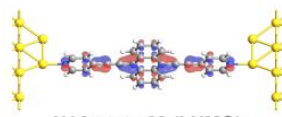

N1A state 69 (LUMO)

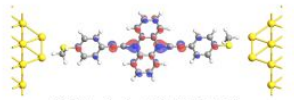

S1A state 81 (LUMO)
$+0.4476 \mathrm{eV}$

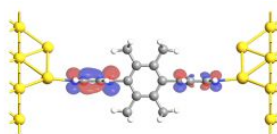

N2 state 56 (LUMO+1) $+0.7332 \mathrm{eV}$

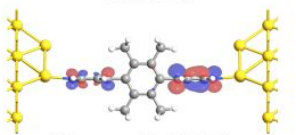

$\mathrm{N} 2$ state 55 (LUMO)
$+0.7241 \mathrm{eV}$

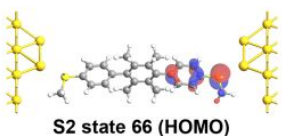

$\mathrm{S} 2$ state 66 (HOMO)
$-1.5362 \mathrm{eV}$

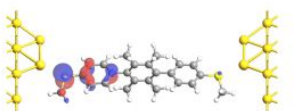

S2 state 65 (HOMO-1) $-1.5796 \mathrm{eV}$

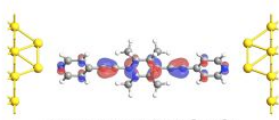

N2A state 62 (номо) $-2.1285 \mathrm{eV}$

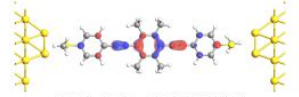

$\mathrm{S} 2 \mathrm{~A}$ state 74 (HOMO)
$-1.3636 \mathrm{eV}$

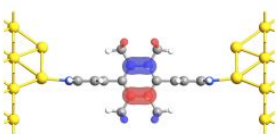

N2 state 54 (HOMO)

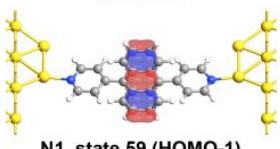

N1 state 59 (HOMO-1) $-3.3290 \mathrm{eV}$

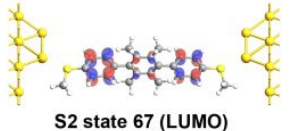

$\mathrm{S} 2$ state 67 (LUMO)
$+\mathbf{+ 2 . 2 9 1 6} \mathrm{eV}$

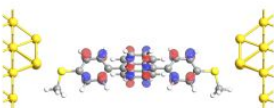
S1 state 74 (LUMO+1)

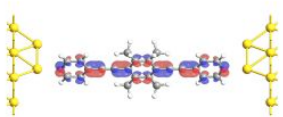

N2A state 63 (LUMO)

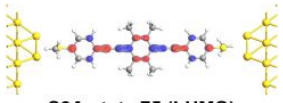

S2A state 75 (LUMO)
$+0.9712 \mathrm{eV}$

Figure S9. Calculated MPSH plots of N1, N2, S1, S2, N1A, N2A, S1A and S2A. The text below each figure show MPSH states and energies related to Fermi energy. The isovalue was set at 0.05 a.u.

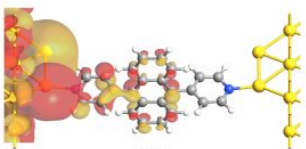

N1

$2.4962 \times 10^{-5}$

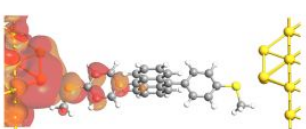

S1

$3.9830 \times 10^{-7}$

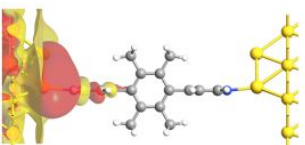

N2

$1.6502 \times 10^{-5}$

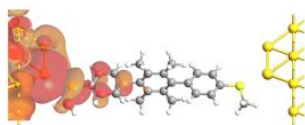

S2

$5.5269 \times 10^{-7}$

Figure S10. Calculated transmission eigenstates at the Fermi energy of N1, N2, S1 and S2. The text below each figure show corresponding transmission eigenstates. The isovalue was set at 0.05 a.u. 


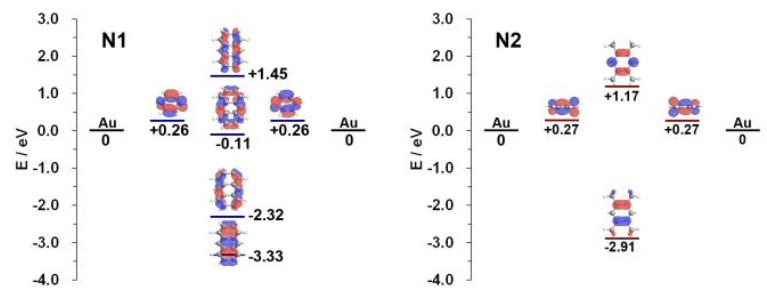

Figure S11. Energy diagrams with plot of corresponding orbital of N1 and N2.

The calculated energy diagrams of $\mathbf{N} 1$ and $\mathbf{N} 2$ are shown in Figure S11., $4 \mathbf{N} 1$ and $\mathbf{N} 2$ are both separated into 3 blocks: 2 anchoring blocks of pyridyl and 1 central block of anthracenediyl in $\mathbf{N} 1$ or tetramethylphenylene in N2. In the energy diagrams, states of every blocks were calculated individually (energies of states are related to Fermi energy). Since anthracene group have excess $\pi$-electrons, 2 more orbitals (at the energy of $-0.11 \mathrm{eV}$ and $-2.32 \mathrm{eV}$ ) were inserted around the Fermi energy by replacing of tetramethylphenylene in $\mathbf{N} 2$ to anthracenediyl in N1, as shown in the Figure S11. The highest occupied orbital of anthracenediyl-core of N1 is close to the lowest unoccupied orbital of pyridiyl groups, indicating the strong intramolecular orbital interaction in N1. The energy of both orbitals are close to the Fermi energy of gold electrodes, leading to resonance transport near the Fermi energy of gold electrodes (Figure S11, left panel). However, the highest occupied orbital and lowest unoccupied orbital of phenylene-core of N2 are far away from the lowest unoccupied orbital of pyridiyl groups. The mismatch between phenylene-core and pyridiyl groups results in the LUMO of N2 away from the Fermi energy of gold electrodes (Figure S11, right panel).

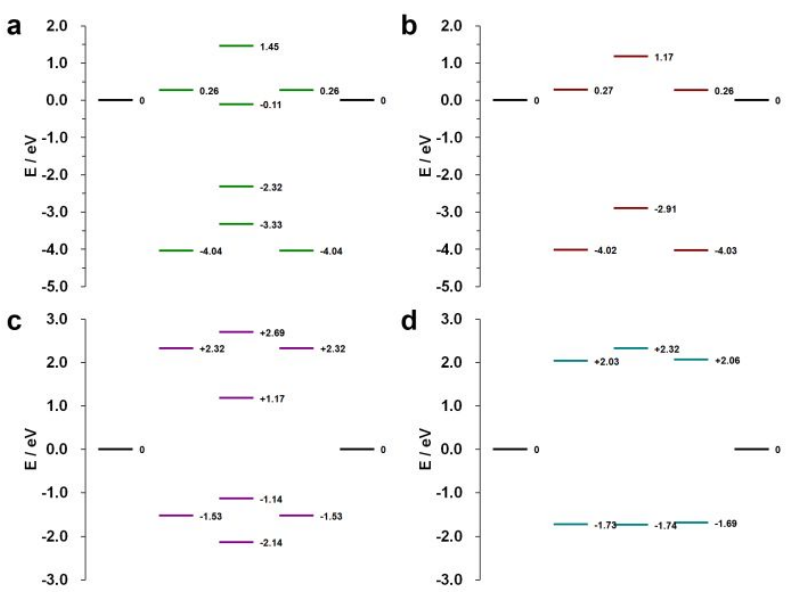

Figure S12. Energy diagrams of (a) N1, (b) N2 (c) S1 and (d) S2. Energies are related to Fermi energy. 

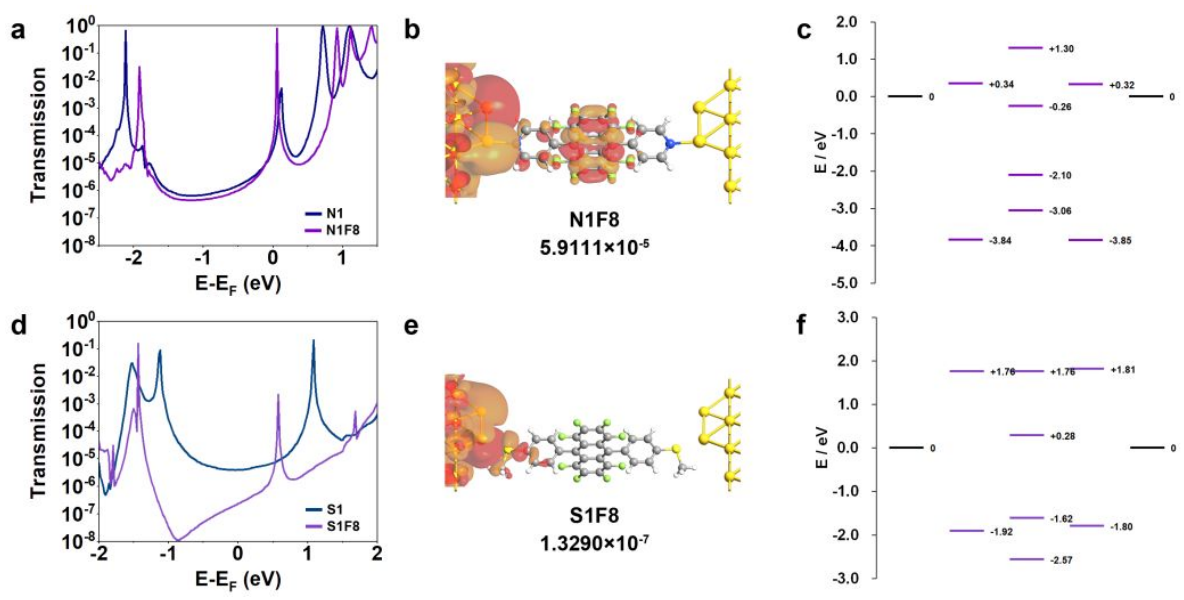

Figure S13. Calculated transmission spectra of (a) N1F8, N1 and (d) S1F8, S1. (b)(e) Calculated transmission eigenstates of (b) N1F8 and (e) S1F8 at the Fermi energy. Energy diagrams of (c) N1F8 and (f) N2F8. Energies are related to Fermi energy.

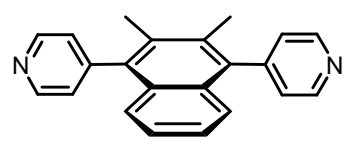

N3

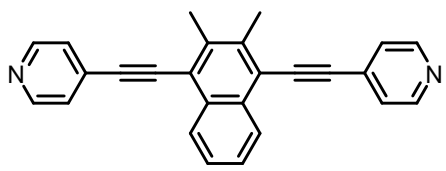

N3A

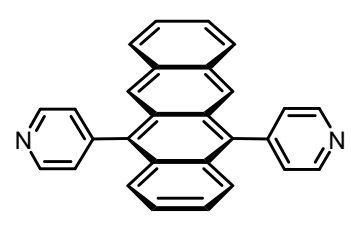

N4

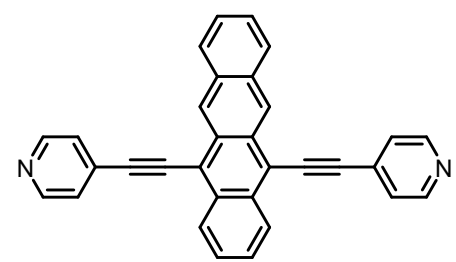

N4A

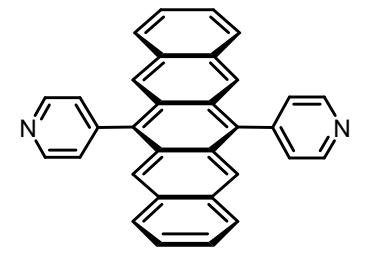

N5

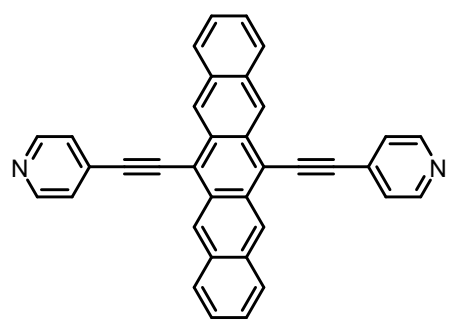

N5A

Figure S14. Molecule structure of N3, N4, N5, N3A, N4A, N5A. 

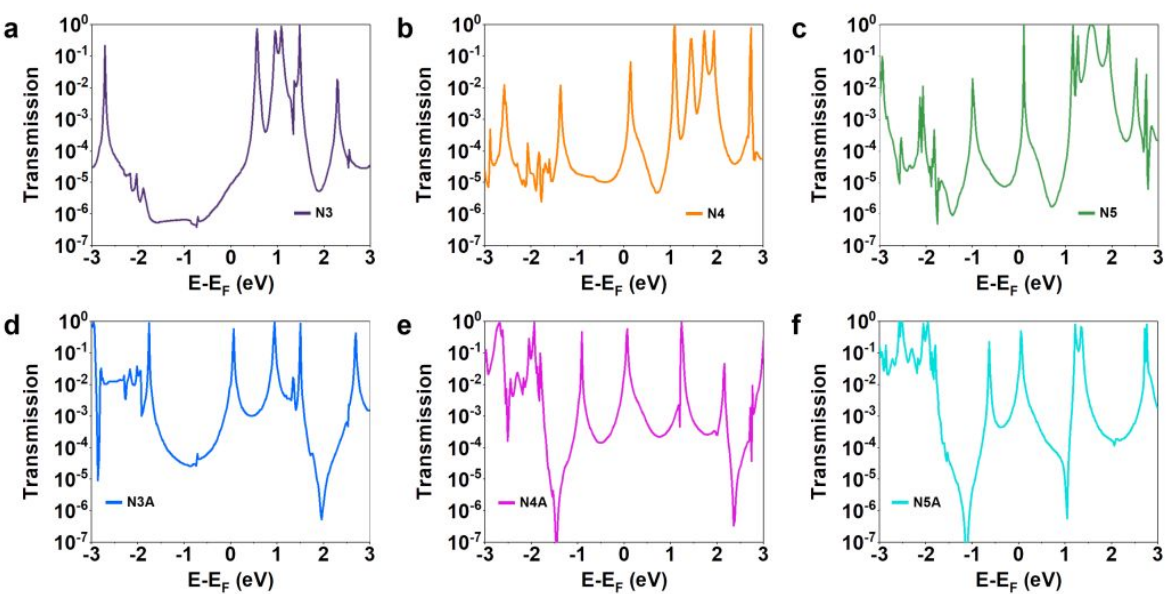

Figure S15. Calculated transmission functions of N3(a), N4(b), N5(c), N3A(d), N4A(e), N5A(f).
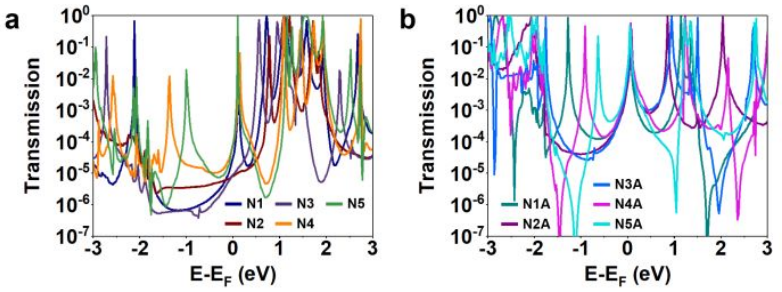

Figure S16. Transmission functions overlapped from all pyridyl-anchored molecules with highly twisted configurations (a) and with highly planar configurations (b).

By replacing central group from phenyl to naphthalenyl, anthracenediyl, tetracenyl, pentacenyl, the transmission functions of N1, N3, N2, N4 and N5 are shown in Figure S16a. The transmission at Fermi energy are gradually increasing with the enlarging of conjugation. However, the transmission at Fermi energy of N1A, N3A, N2A,

N4A and N5A as shown in Figure S16b are almost the same.

\section{Computational details}

All structures for frontier molecular orbitals visual output were optimized at B3LYP/6-311++G(d,p) level of DFT. ${ }^{5-8}$ All the optimizations were performed with the Gaussian 16 software package ${ }^{9}$ at $298 \mathrm{~K}$. In addition, the frequency calculations were performed to confirm the characteristics of the calculated structures as minima. Modredundant optimizations of frozen dihedral angle were used for rotational barriers calculation, calculated every $5^{\circ}$.

The transmission spectra and transmission eigenstates were obtained by using density functional theory (DFT) combined with the non-equilibrium Green's function (NEGF) method as implemented in the Atomistix ToolKit 13.8.0 software package. ${ }^{10-12}$ To construct such a single-molecule device models, all the molecules optimized by Gaussian 16 as described above. Then, each target molecule was attached to the gold atoms in the pyramids at two gold electrodes to fabricate the typical gold-molecule-gold model. The initial Au-N distance is $2.20 \AA$, the initial Au-S distance is $2.50 \AA$. The geometry of entire scattering region is relaxed until all residual forces on each atom are less than $0.05 \mathrm{eV} / \mathrm{A}$. The GGA-PBE exchange correlation functional was adopted. SZP basis set is for Au atoms and DZP basis set is for the other atoms. 

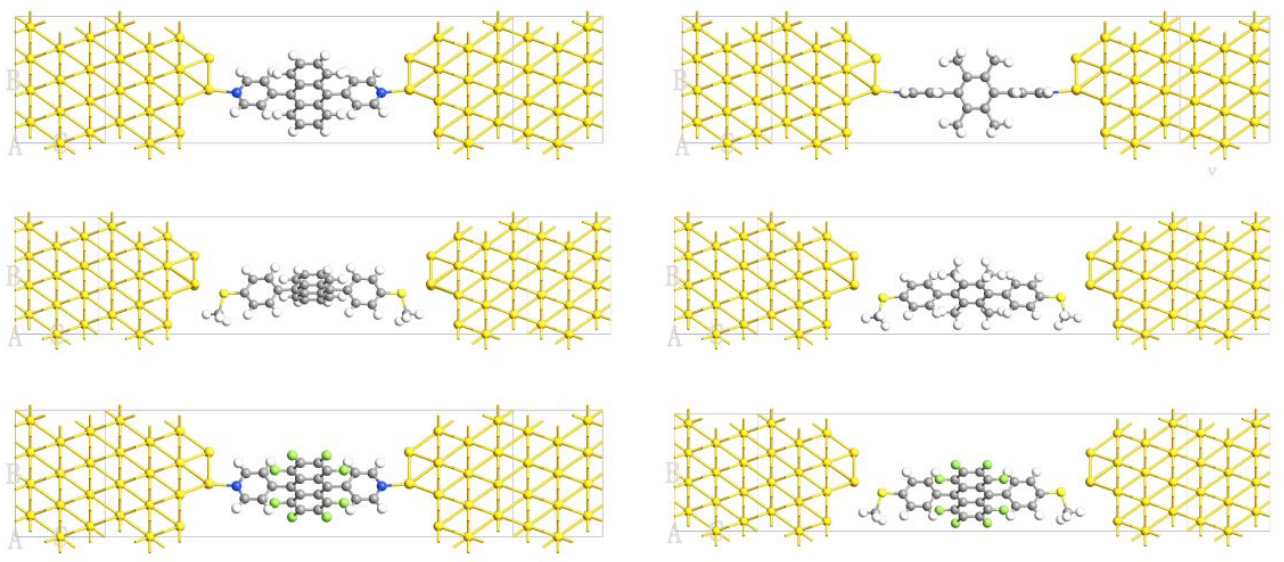

Figure S16. Structures of the optimized molecular devices.

\section{References}

1. Hong, W.; Manrique, D. Z.; Moreno-Garcia, P.; Gulcur, M.; Mishchenko, A.; Lambert, C. J.; Bryce, M. R.; Wandlowski, T., Single molecular conductance of tolanes: experimental and theoretical study on the junction evolution dependent on the anchoring group. J. Am. Chem. Soc. 2012, 134, 2292-304.

2. Hong, W.; Valkenier, H.; Mészáros, G.; Manrique, D. Z.; Mishchenko, A.; Putz, A.; García, P. M.; Lambert, C. J.; Hummelen, J. C.; Wandlowski, T., An MCBJ case study: The influence of m-conjugation on the single-molecule conductance at a solid/liquid interface. Beilstein J. Nanotech. 2011, 2, 699.

3. Vazquez, H.; Skouta, R.; Schneebeli, S.; Kamenetska, M.; Breslow, R.; Venkataraman, L.; Hybertsen, M. S., Probing the conductance superposition law in single-molecule circuits with parallel paths. Nat. Nanotechnol. 2012, 7, 663-667.

4. Widawsky, J. R.; Chen, W.; Vázquez, H.; Kim, T.; Breslow, R.; Hybertsen, M. S.; Venkataraman, L., Length-Dependent Thermopower of Highly Conducting Au-C Bonded Single Molecule Junctions. Nano Lett. 2013, 13, 2889-2894.

5. Hay, P. J.; Wadt, W. R., Ab initio effective core potentials for molecular calculations. Potentials for K to Au including the outermost core orbitals. J. Chem. Phys. 1985, 82, 299-310.

6. Lee, C.; Yang, W.; Parr, R. G., Development of the Colle-Salvetti correlation-energy formula into a functional of the electron density. Phys. Rev. B 1988, 37, 785-789.

7. Miehlich, B.; Savin, A.; Stoll, H.; Preuss, H., Results Obtained with the Correlation-Energy Density Functionals of Becke and Lee, Yang and Parr. Chem. Phys. Lett. 1989, 157, 200-206.

8. Becke, A. D., Density-functional thermochemistry. III. The role of exact exchange. J. Chem. Phys. 1993, 98, 5648-5652.

9. Frisch, M.; Trucks, G.; Schlegel, H.; Scuseria, G.; Robb, M.; Cheeseman, J.; Scalmani, G.; Barone, V.; Petersson,

G.; Nakatsuji, H., Gaussian 16 Revision A. 03. 2016; Gaussian Inc. Wallingford CT 2016.

10. Brandbyge, M.; Mozos, J. L.; Ordejon, P.; Taylor, J.; Stokbro, K., Density-functional method for nonequilibrium electron transport. Phys. Rev. B 2002, 65, 165401.

11. Fan, Z. Q.; Chen, K. Q., Negative differential resistance and rectifying behaviors in phenalenyl molecular device with different contact geometries. Appl. Phys. Lett. 2010, 96, 053509.

12. Capozzi, B.; Xia, J.; Adak, O.; $\quad$ Dell, E. J.; Liu, Z. F.; Taylor, J. C.; $\quad$ Neaton, J. B.; Campos, L. M.; Venkataraman, L., Single-molecule diodes with high rectification ratios through environmental control. Nat Nanotechnol 2015, 10, 522-7. 



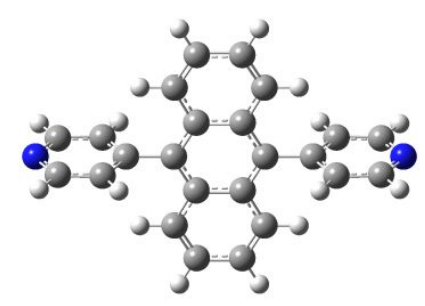

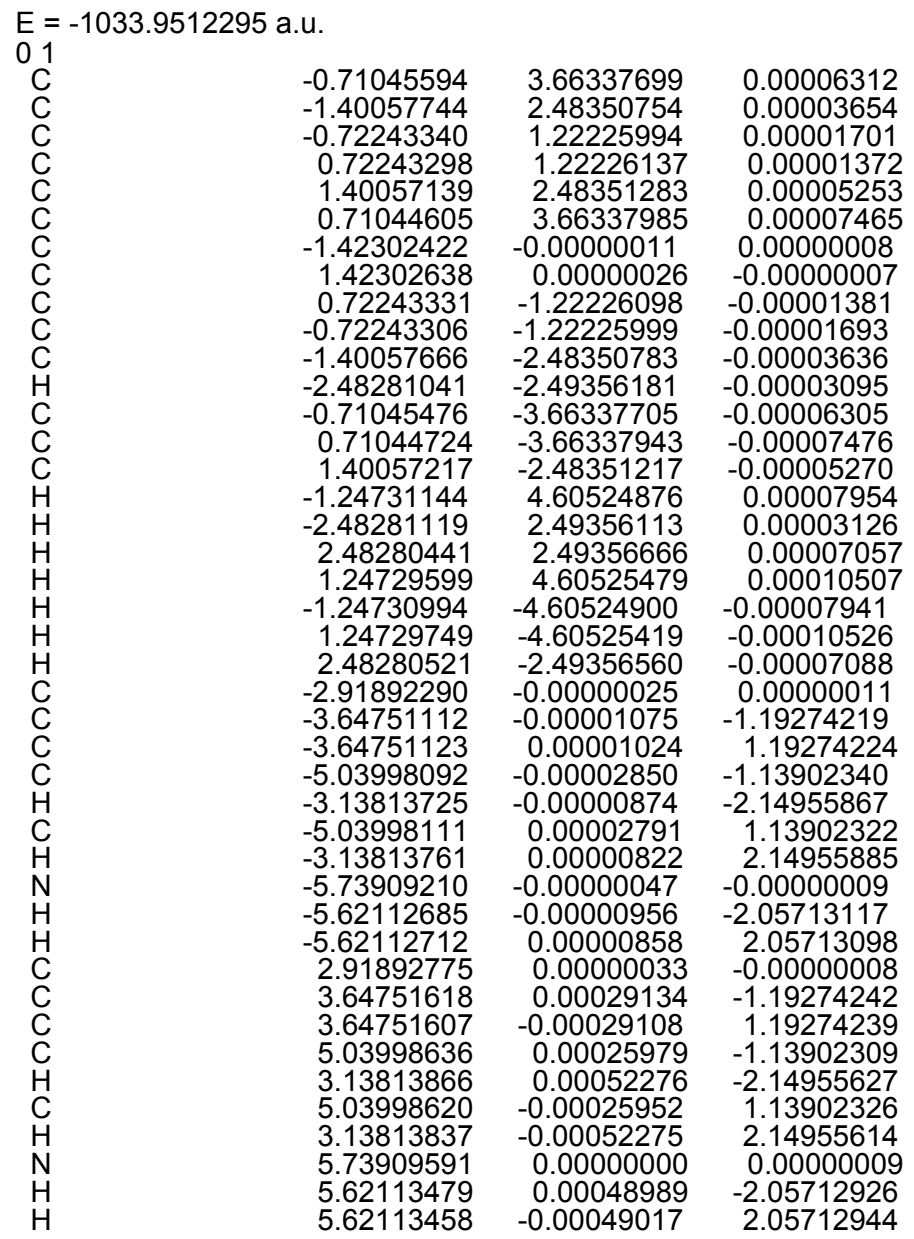




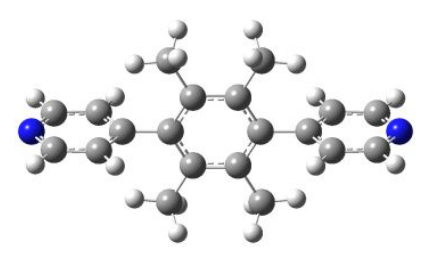

$\begin{array}{lrrr}\text { E }=-883.9061914 \text { a.u. } & & & \\ \text { O } & & & \\ \mathrm{C} & -0.70378166 & -1.22301834 & -0.00032886 \\ \mathrm{C} & 0.70375751 & -1.22303914 & -0.00030030 \\ \mathrm{C} & 1.39843788 & -0.00001684 & -0.00002437 \\ \mathrm{C} & 0.70378144 & 1.22301530 & 0.00025834 \\ \mathrm{C} & -0.70375771 & 1.22302673 & 0.00031993 \\ \mathrm{C} & -1.39842423 & 0.00000989 & -0.00000096 \\ \mathrm{C} & 2.89782330 & -0.00001890 & -0.00001024 \\ \mathrm{C} & 3.62910772 & -0.00053180 & 1.19134044 \\ \mathrm{C} & 3.62913751 & 0.00052279 & -1.19134341 \\ \mathrm{C} & 5.02144756 & -0.00050088 & 1.13844395 \\ \mathrm{C} & 5.02147547 & 0.00050297 & -1.13841196 \\ \mathrm{H} & 5.60230629 & -0.00088420 & 2.05690016 \\ \mathrm{H} & 5.60235710 & 0.00090555 & -2.05685363 \\ \mathrm{C} & -2.89780683 & 0.00001569 & 0.00000248 \\ \mathrm{C} & -3.62909311 & -0.00114634 & 1.19134864 \\ \mathrm{C} & -3.62909477 & 0.00116565 & -1.19134195 \\ \mathrm{C} & -5.02143274 & -0.00109957 & 1.13843413 \\ \mathrm{C} & -5.02143474 & 0.00111998 & -1.13842539 \\ \mathrm{H} & -5.60230534 & -0.00198994 & 2.05688120 \\ \mathrm{H} & -5.60230868 & 0.00199960 & -2.05687172 \\ \mathrm{H} & -3.12066242 & -0.00207461 & 2.14891391 \\ \mathrm{H} & -3.12066595 & 0.00208573 & -2.14890807 \\ \mathrm{H} & 3.12072802 & 0.00095955 & -2.14891937 \\ \mathrm{H} & 3.12067460 & -0.00096159 & 2.14890370 \\ \mathrm{C} & -1.43685856 & 2.54671718 & 0.00076847 \\ \mathrm{H} & -1.17314360 & 3.14575050 & -0.87703592 \\ \mathrm{H} & -2.51715272 & 2.41990708 & 0.00123862 \\ \mathrm{H} & -1.17233347 & 3.14555589 & 0.87845214 \\ \mathrm{C} & 1.43686059 & 2.54671735 & 0.00049009 \\ \mathrm{H} & 1.17286419 & 3.14545433 & 0.87840551 \\ \mathrm{H} & 2.51715737 & 2.41994487 & 0.00029453 \\ \mathrm{H} & 1.17257975 & 3.14583792 & -0.87708200 \\ \mathrm{C} & -1.43691695 & -2.54668879 & -0.00075649 \\ \mathrm{H} & -1.17290959 & -3.14588621 & 0.87684402 \\ \mathrm{H} & -2.51720837 & -2.41984723 & -0.00083345 \\ \mathrm{H} & -1.17271687 & -3.14537648 & -0.87864495 \\ \mathrm{C} & 1.43679758 & -2.54676503 & -0.00050787 \\ \mathrm{H} & 1.17248762 & -3.14567214 & -0.87820857 \\ \mathrm{H} & 2.51709761 & -2.42003120 & -0.00068909 \\ \mathrm{H} & 1.17279008 & -3.14569990 & 0.87727767 \\ \mathrm{~N} & 5.72186961 & 0.00000425 & 0.00002492 \\ \mathrm{~N} & -5.72183923 & 0.00000934 & 0.00000470\end{array}$


N1A

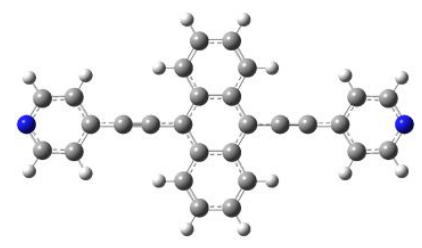

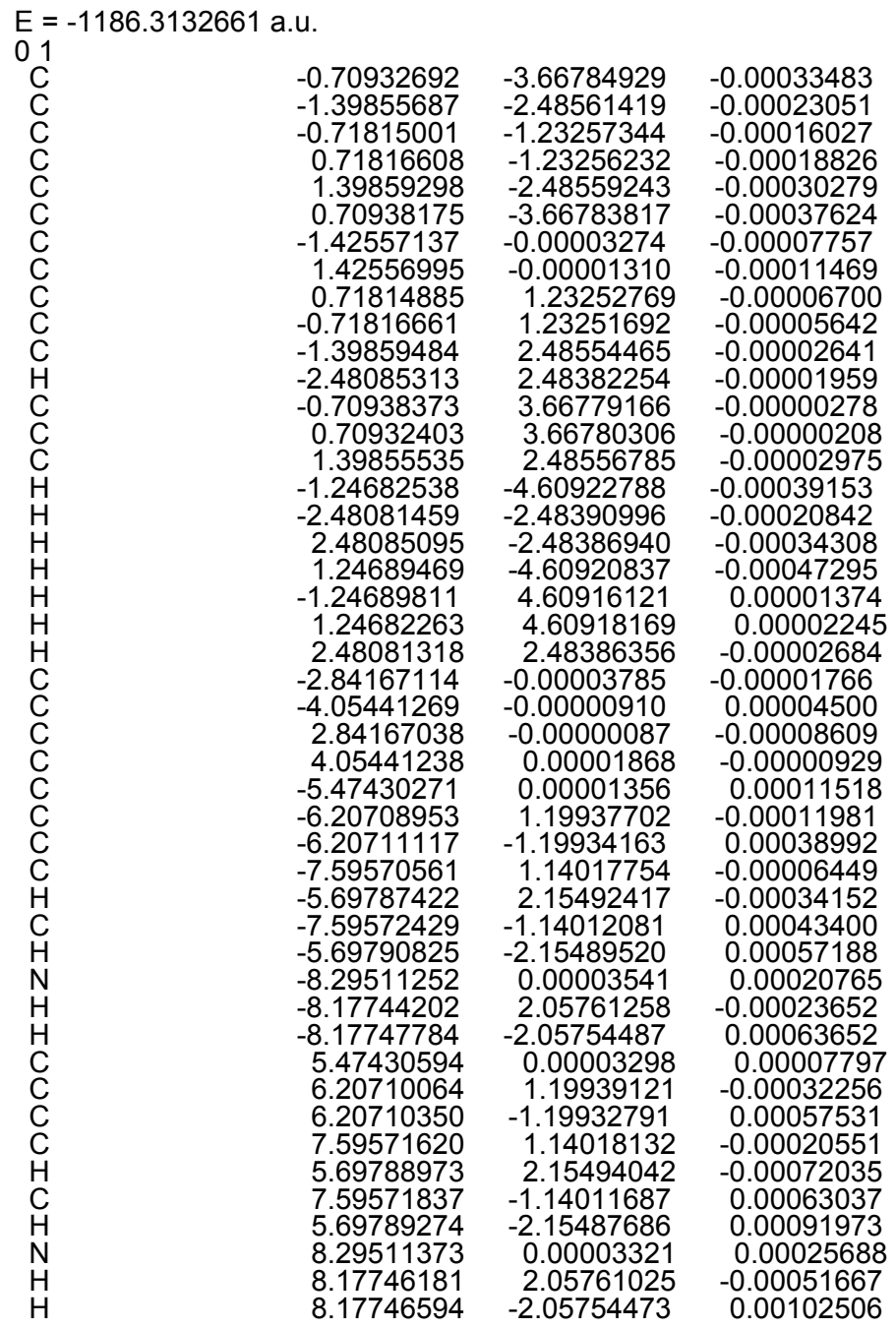




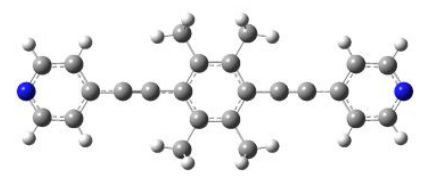

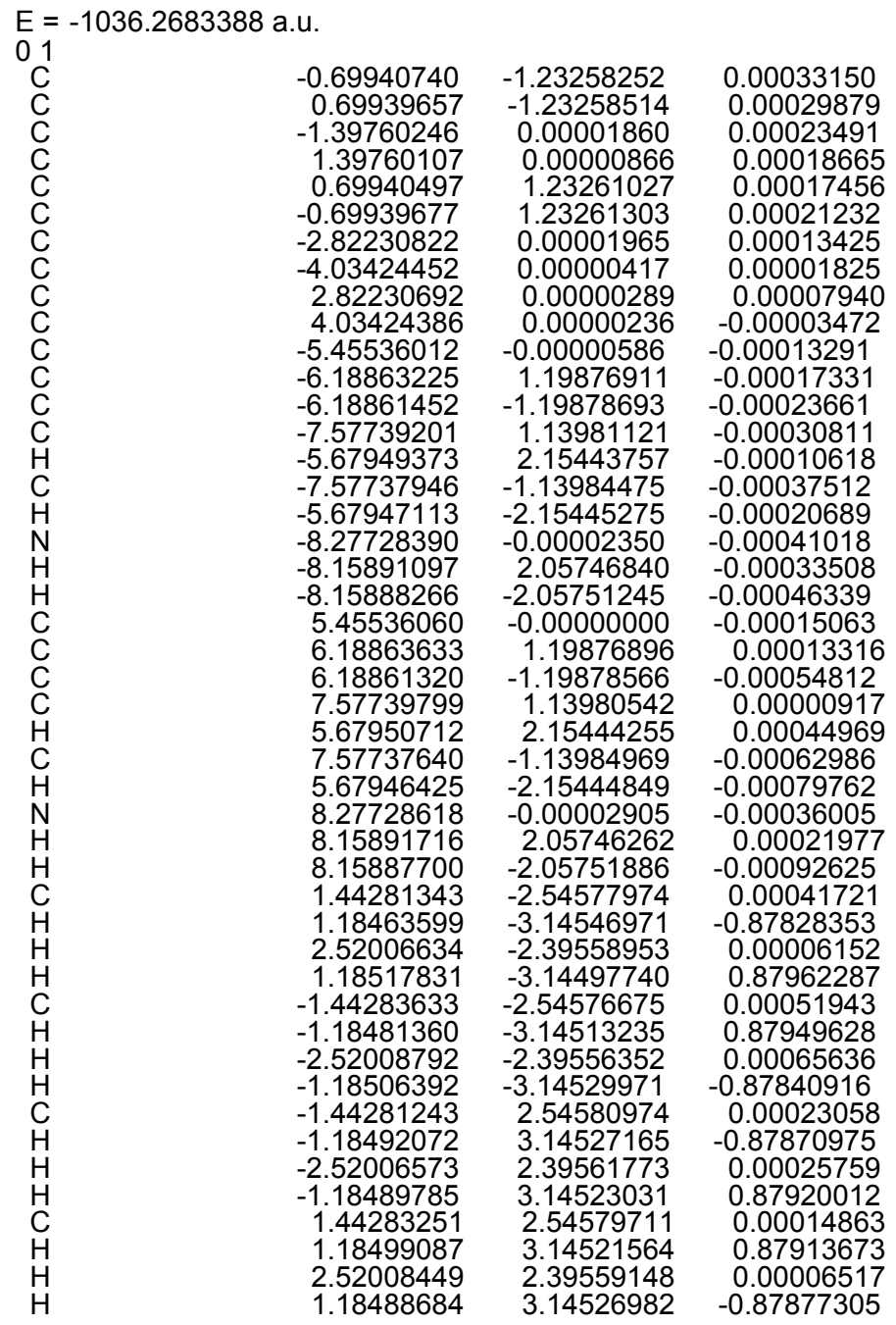




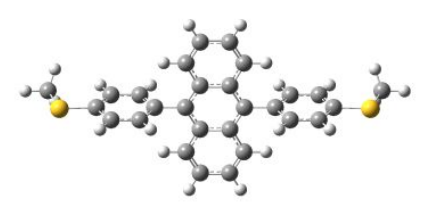

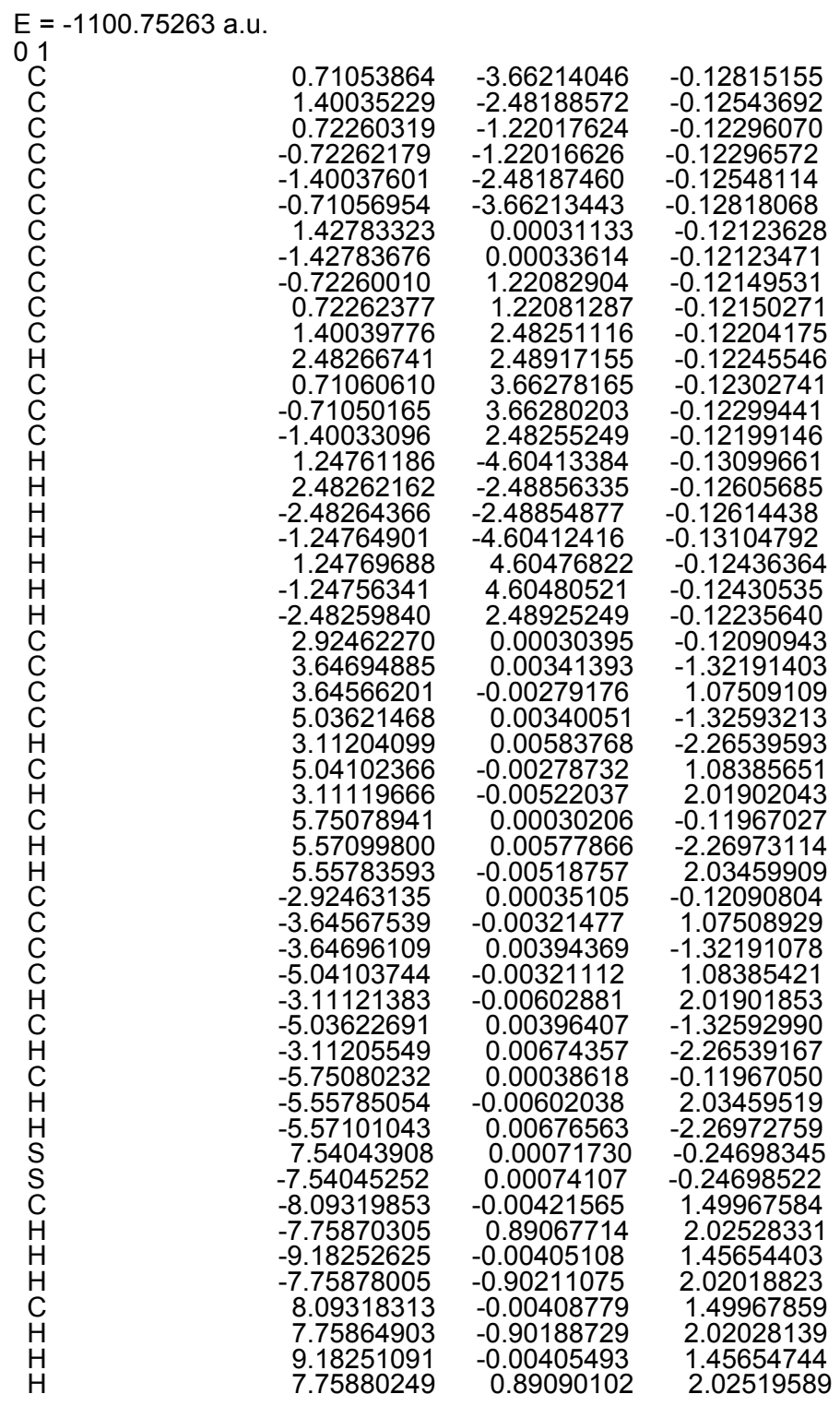




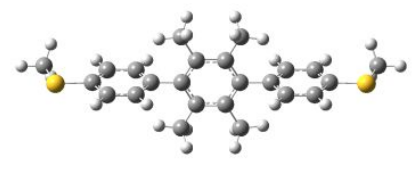

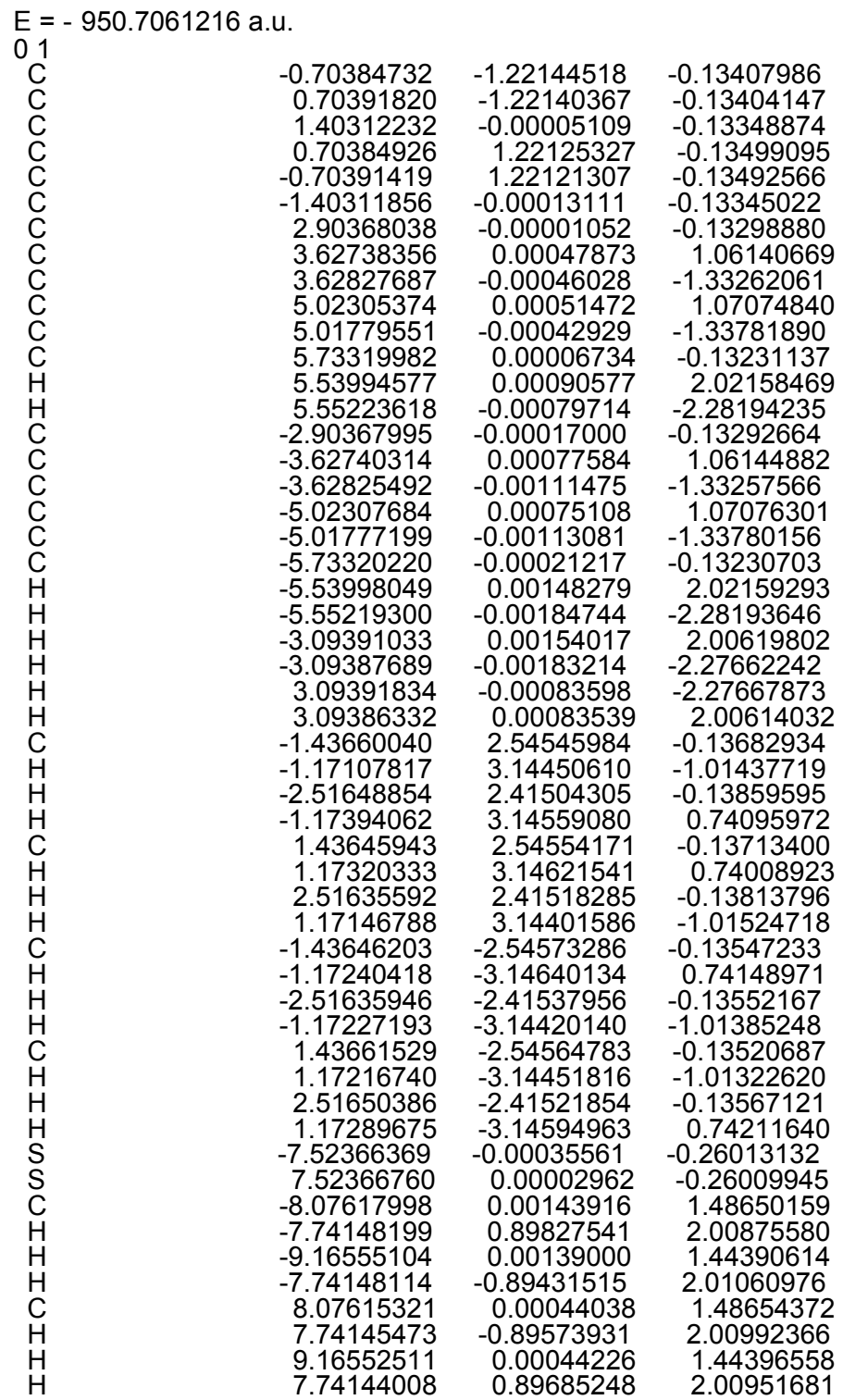




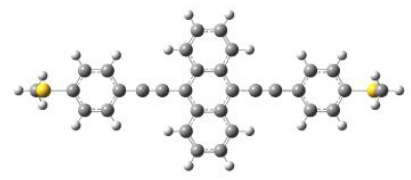

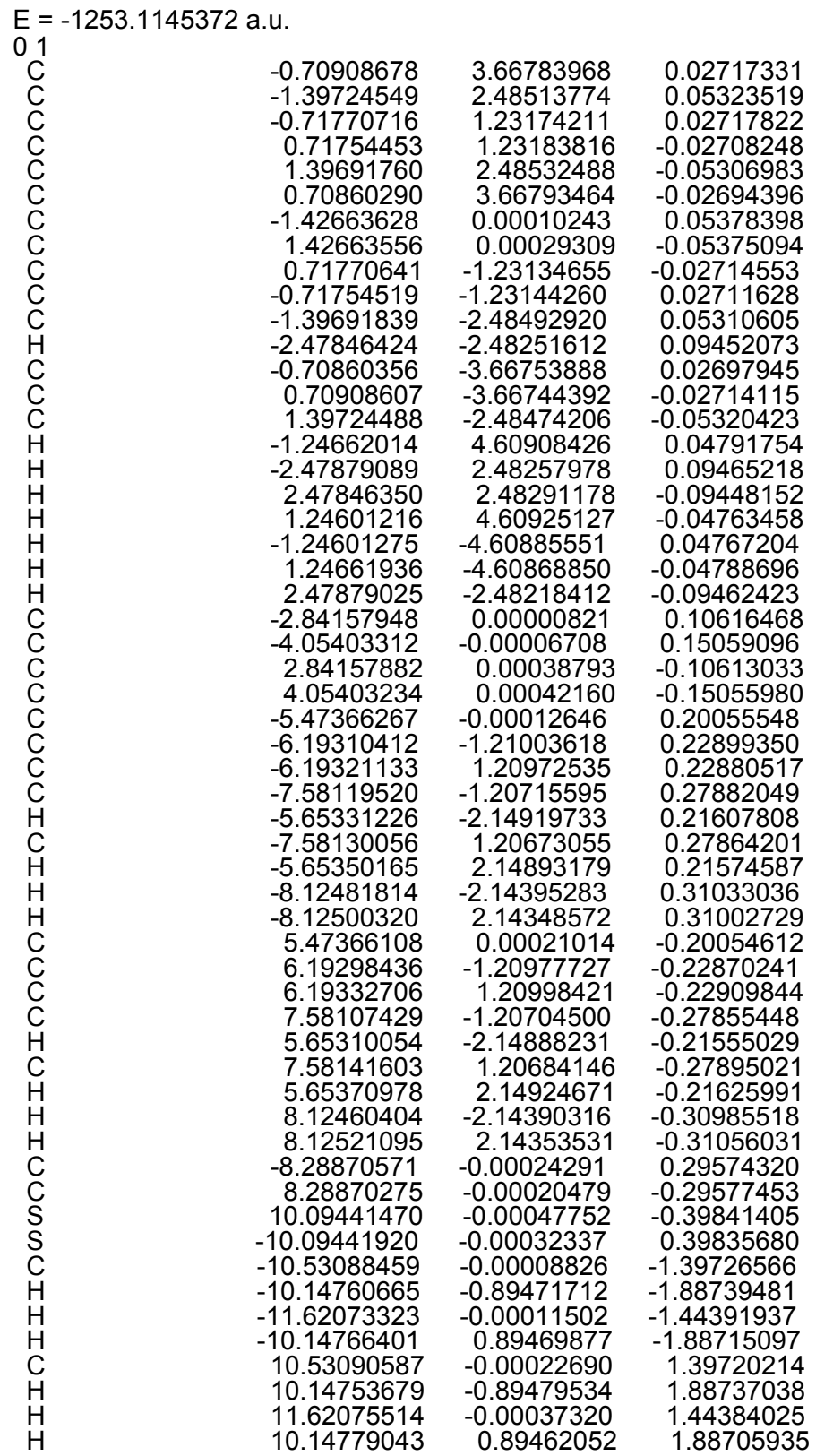




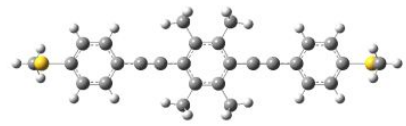

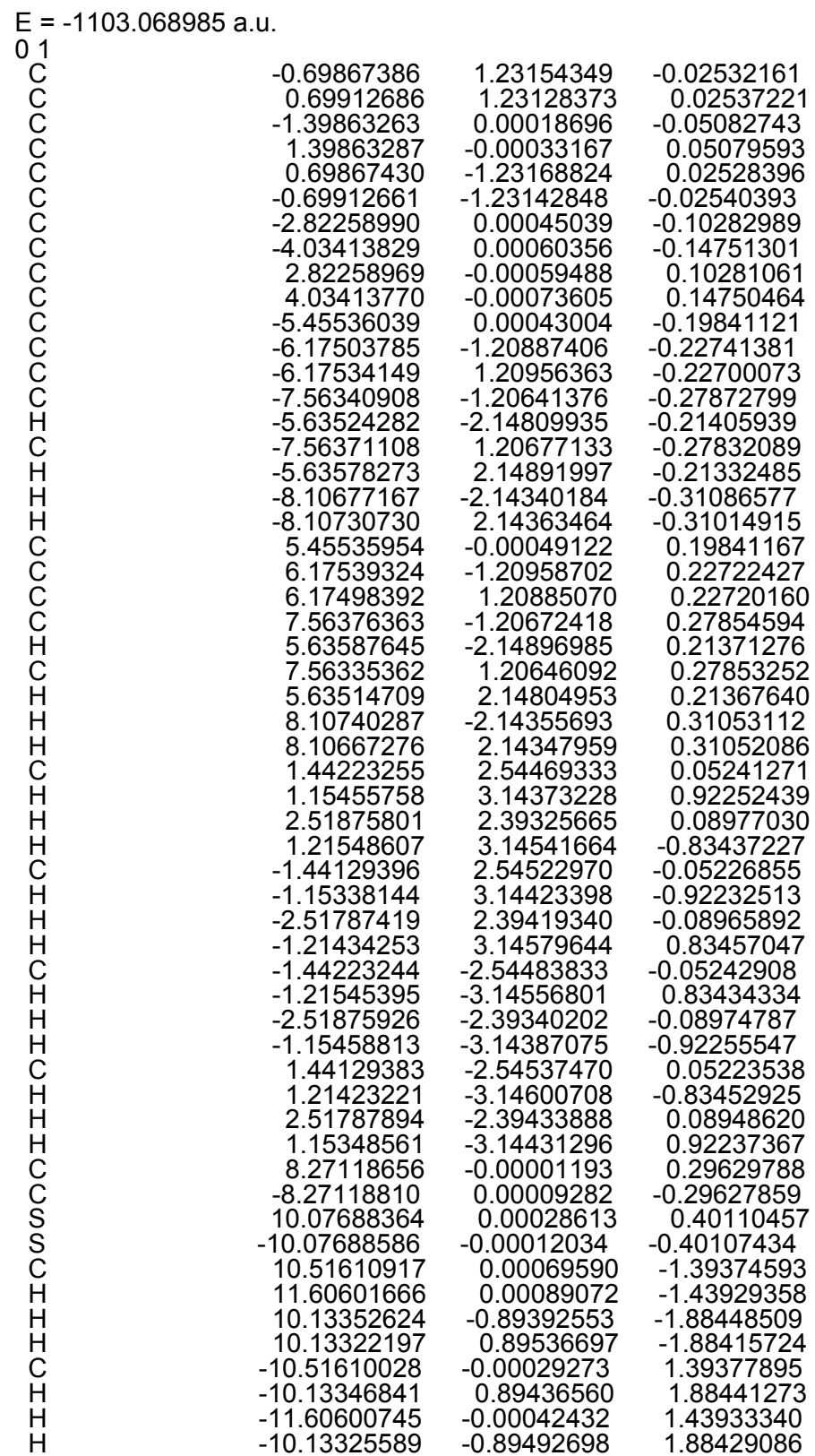

